\title{
The mec-3 gene of Caenorhabditis elegans requires its own product for maintained expression and is expressed in three neuronal cell types
}

\author{
Jeffrey C. Way ${ }^{1,2}$ and Martin Chalfie ${ }^{1}$ \\ ${ }^{1}$ Department of Biological Sciences, Columbia University, New York, New York 10027 USA; ${ }^{2}$ Department of Biology, \\ Princeton University, Princeton, New Jersey 08544 USA
}

\begin{abstract}
The homeo-box-containing gene mec-3 of the nematode Caenorhabditis elegans, is expressed in several sensory neurons, as assayed by expression of a mec-3-lacZ fusion. These cells are the touch receptors, which mediate the response to gentle touch, and the FLP and PVD neurons. PVD mediates a response to harsh mechanical stimuli, and FLP has an ultrastructure suggestive of a mechanoreceptor, but its function is unknown. mec-3 is necessary for the differentiation of the touch receptors, because in mec-3 mutants, the touch receptors do not function and have none of their distinguishing features. mec-3 is also needed for PVD function: The PVD neurons no longer mediate a response to harsh mechanical stimuli in the mutants. The expression of the mec$3-$ lac $Z$ fusion, and presumably mec-3 itself, is altered by mutations in several genes originally identified by their effects on touch cell development. unc-86, another homeo-box-containing gene, is necessary for all mec-3-lacZ expression, but also affects several other lineages and cells in which mec-3 is not expressed. mec-3 activity appears to be required for maintained expression of the mec-3-lacZ fusion in all cells in which it is expressed. In a mec-17 mutant, mec-3-lacZ expression is not maintained in the touch receptors, but is not affected in the FLP and PVD neurons. These findings suggest that combinatorial mechanisms of gene regulation control both the expression of mec-3 itself and its action in promoting the terminal differentiation of various cell types.
\end{abstract}

[Key Words: Caenorhabditis elegans; homeo box genes; autoregulation; neuronal differentiation]

Received August 4, 1989; revised version accepted September 25, 1989.

The determination of identity of particular types of cells is a fundamental aspect of development. As a result of cell-type determination, a characteristic set of proteins is synthesized in a given cell. In single cell organisms, considerable information is available on the regulation of cell type, such as the lysis/lysogeny switch for $\lambda$ phage growth in Escherichia coli (Ptashne 1987) or the determination of mating type in the yeast Saccharomyces cerevisiae (Herskowitz 1988). In each case, the mechanisms by which the regulatory genes controlling these processes are themselves controlled are reasonably well understood.

In contrast, little is known of how regulatory genes act to induce families of cell type-specific structural genes or how the regulators of cell type are themselves regulated in multicellular animals. In Drosophila the determination of the correct cell fate within a region of the developing embryo appears to depend on interactions among a complex pattern of the regulatory genes (for review, see Akam 1987; Ingham 1988), but the molecular mechanisms underlying this combinatorial regulation of development are not well understood.
We have been investigating cell determination by focusing on the mec-3 gene, which controls the identity of the six touch receptor neurons of the nematode Caenorhabditis elegans (Way and Chalfie 1988). The C. elegans nervous system is well suited for the study of determination and differentiation of individual cell types, in part because various neuronal cell types mediate easily assayed, nonessential behaviors. For example, the touch cells mediate the animal's response to gentle touch. Loss of these cells results in a specific behavioral defect that is not mimicked by the loss of any other cell type (Chalfie et al. 1985). Thus, mutations affecting the development and function of this cell type can be identified and distinguished from mutations affecting other classes of cells (Chalfie and Sulston 1981; Chalfie and Au 1989).

Mutational analysis has revealed genes that are necessary for the generation, specification, and function of the touch receptors (Chalfie and $\mathrm{Au} \mathrm{1989).} \mathrm{For} \mathrm{example,} \mathrm{the}$ homeo-box-containing gene unc-86 is necessary for cell lineages that generate the touch receptors. Mutations in unc-86 are pleiotropic: they affect the lineages that gen- 
erate the touch receptors, several other neuronal lineages, and the terminal differentiation of the hermaphrodite-specific neurons (Chalfie et al. 1981, Finney et al. 1988). mec-3 mutants appear to have a defect in the specification of the touch receptors: the pattern of cell division leading to production of these cells is normal, but the cells that are produced have none of the characteristic features of touch receptors. Members of the function class of mutants have recognizable touch receptors that do not mediate a touch response. They appear to encode proteins that are needed for touch receptor activity.

The mec-3 gene contains a homeo box, suggesting that the mec-3 protein binds to DNA to regulate transcription of other genes (Way and Chalfie 1988). From the phenotypes and epistatic interactions of different touchinsensitive mutations, it appears that $m e c-3$ is a regulatory gene that acts upstream of the function genes. A simple hypothesis is that mec-3 may bind to the DNA of the function genes and induce their transcription. One prediction from this hypothesis is that mec-3 should be expressed within the touch receptors. To test this hypothesis, we determined the sites of mec- 3 expression within C. elegans using a mec-3-lacZ fusion. We found that $\beta$-galactosidase is localized not only to the six touch receptors, but also to four other neurons. At least two of these neurons are functionally defective in $\mathrm{mec}-3 \mathrm{mu}$ tants.

To understand how the mec-3 gene is regulated, we examined the expression of the mec-3-lac Z fusion in C. elegans mutants that are defective in touch receptor development. For example, unc-86, which is necessary for touch receptor generation and shares considerable sequence homology with a number of mammalian tran- scription factors (Finney et al. 1988), may regulate mec-3 expression. Our experiments indicate that mec-3 is expressed in a subset of unc-86-dependent lineages, that mec-3 expression depends on unc-86, and that continued expression of mec-3 requires the mec-3 product itself as well as the function of the mec-17 gene.

\section{Results \\ Construction and transformation of a mec-3-lacZ fusion}

To identify sites of mec-3 expression, a C. elegans genetic element was generated from a plasmid carrying a mec-3-lacZ gene fusion, pTU28 (Fig. 1) and a marker plasmid encoding antisense RNA for the unc-22 gene, pPD10.41 (A. Fire, pers. comm.). C. elegans that are transformed with the second plasmid display the twitcher phenotype of unc-22 loss-of-function mutants. The entire mec-3 gene [as defined by rescue of the touch-insensitivity defect of mec-3(u298) after transformation] lies within a $3.5-\mathrm{kb}$ DNA fragment: A series of plasmids containing mec-3 sequences from at least base pairs 1500-5000 all rescue the mec-3(u298) mutant on microinjection [Fig. 1; previous experiments had limited the mec-3 sequence to base pairs $0-5700$ (Way and Chalfie 1988)]. The mec-3 sequences in pTU28 include $3.5 \mathrm{~kb}$ at the $5^{\prime}$ end and $600 \mathrm{bp}$ at the $3^{\prime}$ end in addition to a minimal region required for gene activity. A mixture of pTU28 and pPD10.41 was injected into $C$. elegans. In one transformed animal, the DNAs apparently formed an extrachromosomal element carrying $\sim 40$ copies per cell of each plasmid las estimated by Southern analysis; data not shown). Similar injections of other plasmid mixtures also yield mixed arrays /Stinch-

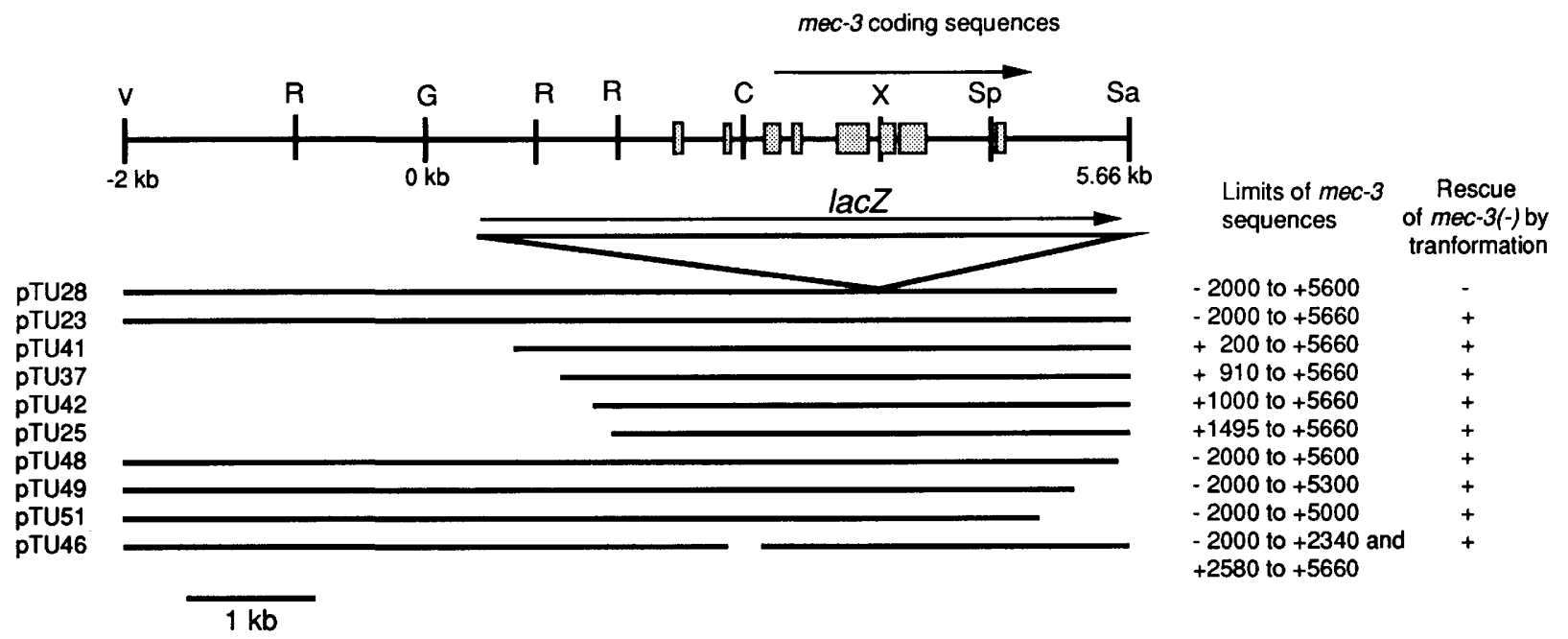

Figure 1. A plasmid containing a mec-3-lacZ fusion and plasmids containing the intact mec-3 gene. pTU28 contains the mec-3 sequences from $-2 \mathrm{~kb}$ to $+5.6 \mathrm{~kb}$ on the sequence of Way and Chalfie (1988). At the XhoI site in the mec-3 homeo box, a 6-kb fragment of DNA containing most of the $l a c Z$ gene has been inserted, generating an in-frame translational fusion. The other plasmids were constructed by deletion of pTU23 as described in Methods. All of these plasmids except pTU28 contain a functional mec-3 gene as defined by transformation rescue of mec-3(u298). The deletion in pTU46 removes the second putative mec-3 exon. Because of the predicted splicing pattern (Way and Chalfie 1988) this result indicates that the first two suggested exons are nonessential for mec-3 function. Restriction site code: (V) EcoRV; (R) EcoRI; (G) BglII; (C) ClaI; (X) XhoI; (Sp) SpeI; (Sa) SalI. 
comb et al. 1985; A. Fire, pers. comm.). This element, termed $u E x 4$, behaves genetically as a free duplication (see Methods). All following experiments use the $u E x 4$ element.

The lac $Z$ fragment in pTU28 disrupts the mec-3 homeo box, so the mec-3 gene in uEx 4 should not be active. The $m e c-3-l a c Z$ fusion construction appears not to confer mec-3 gene activity: mec-3; $u E x 4$ animals are Mec (the touch-insensitive phenotype conferred by a mec-3 mutation; Chalfie and Sulston 1981). Moreover, the $u E x 4$ construction does not interfere with normal mec-3 activity: Wild-type $u E x 4$ animals are not Mec (as much as can be determined in spite of the twitching induced by $u E x 4)$. Furthermore, mec-4(d); uEx4 animals show the touch-receptor degeneration that results from the dominant mec-4(e1611) mutation [mec-4(d)] and that requires mec-3 activity (see below; Chalfie and Sulston 1981; Way and Chalfie 1988).

The mec-3-lacZ fusion is expressed in the touch receptors and the FLP and PVD neurons

$C$. elegans carrying the fusion construction show $\beta$-galactosidase activity, as assayed with the histochemical substrate 5 -bromo-4-chloro-3-indolyl- $\beta$-galactopyranoside (X-gal). Activity is seen in ten cells at $20^{\circ} \mathrm{C}$ : the six touch receptors [the ALML/R, AVM, PVM, and PLML/R cells (L/R, left/right)] and the FLPL/R and PVDL/R neurons (Fig. 2, Table 1). The stained cells were identified by their position, time of appearance, and absence in some mutants and apparent mosaics (see Methods and below).

At a low frequency ( $<5 \%$ of animals examined), other cells are stained: usually these cells are neurons, but occasionally intestinal cells show $\beta$-galactosidase activity. In adult animals that have begun to lay eggs, one or two stained cells were observed in the region of the vulva ( 14 of 47 adults with eggs) and anterior to FLP (7 of 52 animals). These cells were not identified. In addition, the frequency of the unusual, faintly staining cells is increased in animals raised at $25^{\circ} \mathrm{C}$. In older adults $>20$ eggs) the cells that stain occasionally are one to seven neurons in the ventral cord between the vulva and the preanal ganglion, and two cells that may be the AIZ cells, the FLP sisters. We do not know the significance of this staining because it is only seen long after these cells arise, is strongly temperature-dependent, and is generally seen in animals that appear overstained in the touch, FLP, and PVD cells.

Because C. elegans neurons are small and have little cytoplasm, it is difficult to determine whether the $\beta$-galactosidase activity is localized to the nucleus or to the cell body in staining neurons. However, when the large intestinal cells are stained, the blue X-gal reaction product is clearly localized to the nucleus and not the entire cell. This suggests that the mec-3 protein contains a nuclear localization sequence between the amino-terminus and the site of the $1 a c Z$ fusion.

In an otherwise wild-type animal carrying the mec-3lac $Z$ fusion, the touch receptors and the FLP and PVD neurons continue to express $\beta$-galactosidase activity throughout the life span of the animal. For the AVM and PVM touch cells and the PVD neurons [all postembryonic cells [Sulston and Horvitz 1977)] staining begins at approximately the time when the cells arise from their respective lineages. We do not know whether the immediate precursors of these cells also stain, because the precursors exist for only about $2 \mathrm{hr}$ before dividing.

\section{Effect of touch-receptor mutations on mec-3-lacZ fusion expression}

To determine whether mutations that alter touch receptor development affect the expression of the mec-3 product, the $u E_{X} 4$ element was crossed into several mutant strains (see Methods). Expression of $\beta$-galactosidase from the $u E x 4$ element was examined in unc-86(e1416), mec-3(u298), mec-4(d; e1611), and mec-17(u265) backgrounds.

In the unc-86(e1416) mutant, no staining is seen in the normal positions of the touch receptors and the FLP and PVD cells. unc-86 mutants show alterations in the lineages that produce these cells [Chalfie et al. 1981; Chalfie and Sulston 1981; J. Sulston, unpubl. (as cited in Finney 1987]. Occasionally, a novel cell will stain [not one of the usual set; 2 of 25 animals examined), but most animals show no staining at all.

In the mec-3(u298) mutant, the fusion is initially expressed in the correct cells, but $\beta$-galactosidase activity in these cells is not seen at later stages of development (Table 1). For example, the ALM, PLM, and FLP cells arise $6 \mathrm{hr}$ before hatching in animals grown at $20^{\circ} \mathrm{C}$ (Sulston et al. 1983). Staining of these cells can be seen (at a reduced frequency) within $6 \mathrm{hr}$ after hatching. Twenty hours later, in the middle of larval development, these cells no longer stain. Because $\beta$-galactosidase activity is seen in wild-type animals throughout development, it appears that an intact mec-3 gene is necessary for the continuous expression of the mec-3-lacZ fusion. (These observations also suggest that the RNA and protein products of the mec-3-lac $Z$ gene fusion have a lifetime of less than about $32 \mathrm{hr}$. It is formally possible that mec-3 acts to stabilize the fusion protein or mRNA, but this seems unlikely.)

In animals carrying the mec-4(d) mutation, the touch receptors degenerate. mec-4(d) appears to encode a toxic form of the mec-4 product that causes cells in which it is expressed to die /Chalfie and Sulston 1981; Herman 1987). No staining corresponding to the touch receptors is seen in adult mec-4(d); $u E x 4$ animals. This observation uniquely identifies the touch receptors as staining cells because no other cell type reproducibly degenerates in mec-4(d) mutants (Chalfie and Sulston 1981; Way and Chalfie 1988). [Occasionally, in an L4 animal, a stained AVM or PVM cell can be seen (Table 1). These cells do not always degenerate by this stage /Chalfie and Sulston 1981).| B-Galactosidase activity continues to be observed in the PVD and FLP cells, which apparently do not degenerate in the $m e c-4(d)$ background.

Expression of mec-3-lacZ was also tested in 

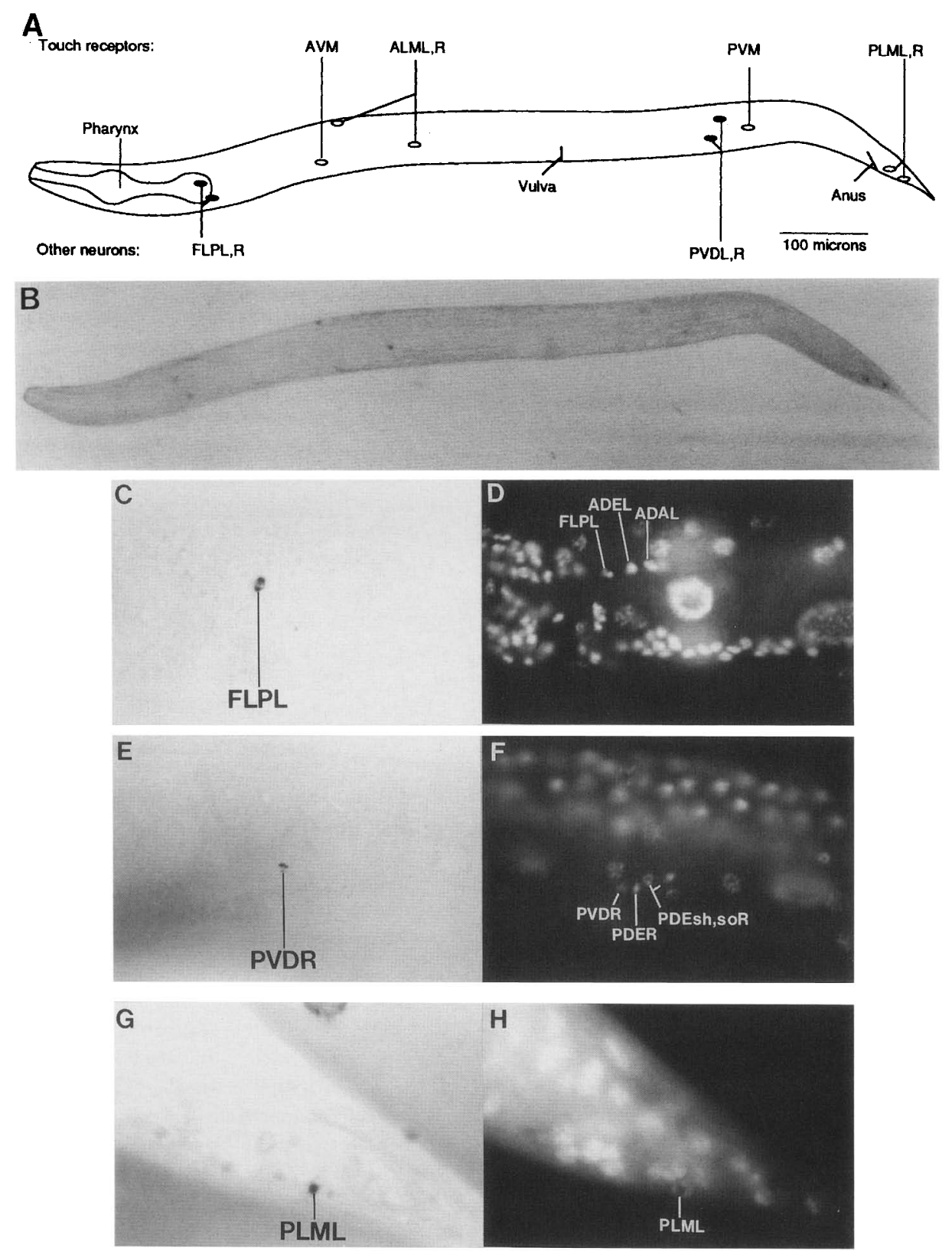

Figure 2. Cells expressing the mec-3-lacZ fusion in an adult C. elegans hermaphrodite. $(A)$ Schematic diagram of the five pairs of cells that express $\beta$-galactosidase activity in adults carrying the $u E x 4$ element. The FLP, ALM, PVD, and PLM neurons are found as bilaterally symmetric pairs; the AVM and PVM neurons arise from virtually identical lineages but are asymmetrically positioned as a result of different migration patterns of their precursors (Sulston and Horvitz 1977). (B) $\beta$-Galactosidase staining in a young adult (the AVM, PVM, and PVD, neurons are stained too faintly to be seen clearly at this magnification). ( $C, E$, and $G$ ) Bright-field exposures of the FLPL, PVDR, and PLML neurons stained with X-gal. $(D, F$, and $H)$ Same cells and neighboring nuclei stained with the nuclear fluorescent dye DAPI.

mec-17(u265) mutant animals. In mec-17, the touch receptors function normally in newly hatched animals, but touch sensitivity is lost as the animals mature (Chalfie and Au 1989). In mec-17 mutants carrying the $m e c-3-1 a c Z$ fusion, the frequency of staining of the touch receptors is reduced by about threefold, whereas the PVD and FLP neurons stain normally. Of the embryonically derived mec-3-lacZ-expressing cells, only $37 \%$ (84 of 228) of the touch cells (ALML/R and PLML/R) were stained, whereas $91 \%$ (102 of 112 ) of the FLP cells were stained in L4 larvae and adults (Table 1). The reduction in $\beta$-galactosidase activity in the touch receptors occurs in the middle of larval development, at about the same time as the reduction in touch-sensitivity of mec-17 animals (Table 1; Chalfie and Au 1989). [The AVM/PVM staining appears normal in mec-17 adults (Table 1). We do not know whether or not the presence of staining is a reflection of the relative age of 
Table 1. Expression of the mec-3-lacZ fusion in wild-type and mutant strains

\begin{tabular}{|c|c|c|c|c|c|c|c|}
\hline \multirow[b]{2}{*}{ Strain } & \multirow[b]{2}{*}{ Stage } & \multirow[b]{2}{*}{$\begin{array}{l}\text { Number of } \\
\text { animals }\end{array}$} & \multicolumn{5}{|c|}{ Cells stained $(\%)$} \\
\hline & & & $\mathrm{ALML} / \mathrm{R}$ & $A V M+P V M$ & PLML/R & FLPL/R & $\mathrm{PVDL} / \mathrm{R}$ \\
\hline \multirow{4}{*}{ Wild type } & $\mathrm{L} 1$ & 24 & 58 & 2 & 73 & 44 & NA \\
\hline & $\mathrm{L} 2 / \mathrm{L} 3$ & 12 & 58 & 8 & 38 & 38 & 46 \\
\hline & L4 & 15 & 83 & 43 & 70 & 70 & 63 \\
\hline & adult & 36 & 75 & 38 & 68 & 81 & 78 \\
\hline \multirow[t]{2}{*}{ at $25^{\circ} \mathrm{C}$} & $\mathrm{L} 1$ & 18 & 83 & 39 & 89 & 67 & NA \\
\hline & adult & 25 & 88 & 68 & 84 & 96 & 92 \\
\hline \multirow[t]{2}{*}{ unc-86 } & $\mathrm{Ll}$ & 18 & 0 & 0 & 0 & 0 & NA \\
\hline & L4/adult & 7 & 0 & 0 & 0 & 0 & 0 \\
\hline \multirow[t]{3}{*}{$m e c-3$} & $\mathrm{~L} 1$ & 21 & 5 & 2 & 26 & 29 & NA \\
\hline & $\mathrm{L} 2 / \mathrm{L} 3$ & 13 & 0 & 8 & 0 & 0 & 8 \\
\hline & adults ${ }^{\mathbf{a}}$ & 12 & 0 & 0 & 0 & 0 & 0 \\
\hline$m e c-4(d)$ & L4/adults & 27 & 0 & 17 & 0 & 78 & 35 \\
\hline mec-17 & $\mathrm{Ll}$ & 10 & 85 & 0 & 85 & 75 & NA \\
\hline at $25^{\circ} \mathrm{C}$ & adults & 22 & 11 & 68 & 43 & 100 & 91 \\
\hline mec-17 unc-24 & $\mathrm{L} 1 / \mathrm{L} 2$ & 24 & 90 & 50 & 65 & 44 & 13 \\
\hline \multirow{3}{*}{ at $25^{\circ} \mathrm{C}$} & L3/young L4 & 13 & 72 & 45 & 68 & 70 & 89 \\
\hline & L4/young adult & 15 & 37 & 20 & 33 & 80 & 53 \\
\hline & adult with eggs & 20 & 35 & 48 & 38 & 85 & 88 \\
\hline
\end{tabular}

Animals were identified as carrying the $u E x 4$ element by their Twitcher phenotype and stained with X-gal. Each cell column represents a pair of cells in each animal. The stage of development was determined either by synchronizing animals at hatching (for L1, L2, and L3 animals) or by examining the development of the gonad and the presence of fertilized eggs. In embryos, it was not possible to identify staining cells. However, embryos with more than six staining cells (i.e., having more than embryonic FLP, ALM, and PLM cells) were not seen. (NA) Not applicable; PVD cells do not arise until the L2 stage.

a Ten of twelve mec-3; $u E x 4$ adults contained embryos that stained with X-gal.

these postembryonic cells compared to that of the ALM and PLM cells.]

\section{The PVD neurons mediate a response to a strong mechanical stimulus}

Two observations argue that the chromosomal mec-3 gene is normally expressed in the FLP and PVD neurons: (1) the mec-3-lac $Z$ fusion is expressed in these cells, and (2) the wild-type chromosomal gene is needed to maintain expression of the fusion in these cells. Therefore, we sought to identify a behavior mediated by the PVD and FLP neurons and to determine whether this function was altered in mec-3 mutants. Ward et al. (1975) and E. Hedgecock (pers. comm.), respectively, suggested that the FLP and PVD neurons may be mechanosensory receptors on the basis of their ultrastructure. Each FLP cell has an anterior process with a ciliated ending that is characteristic of many mechanosensory cells. The PVD cells have long anterior and posterior processes that make essentially no synapses, and which therefore may be sensory processes. Both the PVD and FLP cells have ventral processes that synapse onto the interneurons that control forward and backward movement (White et al. 1986).

To test this possibility, animals with or without PVD neurons (and lacking the touch receptors) were tested for their response to a strong mechanical stimulus: a prodding with a platinum wire to the midsection of the body. Several mutant and laser-ablated animals were tested in blind experiments (Table 2). unc-86 and lin-32(u282) mutants, which lack PVD cells and all or some of the touch receptors, failed to respond to this stimulus. mec-4(d) animals, in which the PVD cells appear to be normal but the touch receptors degenerate, responded to being prodded with a platinum wire, usually by moving backwards.

When the PVD neurons are eliminated from mec-4(d), either by laser ablation of PVD or its precursor V5, the response to prodding is lost (Table 2). Ablation of the neighboring cells (V4 or neurons adjacent to PVD) had no effect on this behavior. These results suggest that the response to strong mechanical stimulus is mediated by the PVD cells, and that this behavior can be used to assay PVD function.

\section{mec-3 is required for $P V D$ function}

Most mec-3 mutants do not respond when similarly prodded with a platinum wire, which suggests that mec-3 is needed for proper function of the PVD neurons as well as for that of the touch receptors (Table 2). [mec-3/u312) mutants do respond in this assay, but this mutation appears to be hypomorphic because it only partially fails to complement other mec-3 mutations for touch insensitivity ( $M$. Chalfie, unpubl.).] In blind experiments in which mec3, mec-4(d), and unc-86 animals are mixed and tested for sensitivity to the platinum wire, mec-3 and unc-86 animals are equally insensitive and easily distinguished from the sensitive mec-4(d) animals (Table 2).

Because of the apparent loss of PVD function, we 
Table 2. Sensitivity of C. elegans strains to a strong mechanical stimulus

\begin{tabular}{|c|c|c|c|}
\hline $\begin{array}{l}\text { Genotype or } \\
\text { cells ablated }\end{array}$ & $\begin{array}{l}\text { Response to } \\
\text { harsh touch }\end{array}$ & $\begin{array}{l}\text { Number responding } \\
\text { out of total }\end{array}$ & $\begin{array}{l}\text { Relevant touch receptor } \\
\text { or PVD phenotype }\end{array}$ \\
\hline$m e c-4(d ; e 1611)$ & + & $15 / 16$ & touch receptors degenerate \\
\hline unc-86(e1416) & - & $0 / 8$ & touch receptors and PVD absent because of lineage alterations $\mathrm{s}^{\mathrm{c}}$ \\
\hline $\operatorname{lin}-32(u 282)$ & - & & $\begin{array}{l}\text { AVM, PVM, and PLM touch receptors absent, PVD absent } \\
\text { because of lineage alterations }\end{array}$ \\
\hline$m e c-4(d ; e 1611)$ & & & touch receptors degenerate \\
\hline V5 ablated & - & $2 / 9$ & PVD absent \\
\hline V4 ablated & + & $6 / 6$ & PVD present \\
\hline PVD ablated & - & $1 / 6$ & PVD absent \\
\hline unlasered & + & $7 / 8$ & PVD present \\
\hline$m e c-3(e 1338)$ & - & & touch receptors fail to express \\
\hline (e1498) & - & $0 / 6$ & any specific features; PVD \\
\hline (e1612) & - & & nonfunctional (as indicated here) \\
\hline (u6) & - & & \\
\hline$(u 81)$ & - & $0 / 8$ & \\
\hline (u99) & - & $2 / 5$ & \\
\hline (u184) & - & & \\
\hline (u298) & - & $2 / 16$ & \\
\hline (u312) & + & & \\
\hline $\operatorname{mec}-1(e 1336)$ & + & & touch receptors differentiate correctly, \\
\hline mec-2(u447) & + & $8 / 8$ & but do not function; \\
\hline $\operatorname{mec}-4(u 441)$ & + & $8 / 8$ & PVD functional (as indicated here) \\
\hline $\operatorname{mec}-5(e 1340)$ & + & & \\
\hline $\operatorname{mec}-6(u 450)$ & + & & \\
\hline mec-7(u433) & + & & \\
\hline mec-8(e398) & + & $8 / 8$ & \\
\hline mec-9(u258) & + & & \\
\hline mec-10(e1715) & + & $7 / 7$ & \\
\hline mec-12(e1605) & + & & \\
\hline mec-14(u82) & + & $6 / 8$ & \\
\hline mec-1(e1336); mec-7(e1505) & + & & \\
\hline
\end{tabular}

all strains were tested for sensitivity to a strong mechanical stimulus by examining animals of known genotype.

bSeveral strains were tested in blind experiments in which individual animals were picked to separate plates and scored in ignorance of the animal's genotype. All laser-ablated animals were scored in blind tests along with unablated animals or control ablations (see Methods).

'Chalfie et al. 1981.

dChalfie and $\mathrm{Au} 1989$.

wished to determine whether the PVD neurons were morphologically altered in a mec-3 mutant. mec-3 mutations cause two of the touch receptors, the ALM cells, to resemble their lineage sister neurons (Way and Chalfie 1988). We sought to test whether, in a mec-3 mutant, the PVD neurons also resemble their sister cells, which undergo programmed cell death. The PVD neurons were examined in ced-1; mec-3(u298) and ced-1; mec-3 $(+)$ strains. [Normal cell deaths, when viewed with Nomarski optics, are refractile for about 30 min (Sulston and Horvitz 1977); ced-1 causes cells undergoing programmed cell deaths to remain refractile for several hours (Hedgecock et al. 1983).] Eleven of 12 mec-3; ced-1 animals examined in the early L3 stage showed refractility of the PVD sister cell, whereas PVD appeared intact. In one animal, the PVD neuron could not be distinguished from other cells in the post-deirid cluster of neurons, and one neuron was missing from this group. Ten ced-1; mec-3(+) animals observed at the same stage had the normal pattern of neurons and cell deaths (Ellis and Horvitz 1986). Thus, loss of mec-3 activity does not cause the PVD cells to assume a fate like their sisters. In addition, the characteristic large size and position of the cells bodies of the PVD cells do not appear to be altered in mec-3(u298) mutants observed with Nomarski optics.

The fate of the PVD sister cell was unaffected by the mec-3 mutation: This cell still underwent programmed cell death. Thus, it appears that mec-3 acts only on a single cell at the end of a lineage (PVD in this case), rather than in a precursor cell.

Several strains with $m e c$ mutations of the function class (mec-1, mec-2, mec-4, mec-5, mec-6, mec-7, mec-8, mec-9, mec-10, mec-12, and mec-14, and the double mutant mec- 1 ; mec-7) respond normally to prodding with a platinum wire (Table 2). These genes may encode products that are used only in the touch receptors and not in the PVD cells. Alternatively, mutations in these genes may only debilitate partially the touch receptors with the effect of raising the threshold stimulus: In these mutants, the touch receptors could mediate a response to a strong stimulus but not to gentle touch.

It is unclear whether FLP also mediates a response to a mechanical stimulus. unc-86 animals, which lack FLP, 
respond when prodded on the pharynx, in the region of the FLP sensory process. Because a number of additional, putative mechanosensory neurons exist in the head (Ward et al. 1975), any of these could mediate a response in the absence of FLP.

\section{Discussion}

mec-3 is expressed in several classes of mechanoreceptors

Originally, mec-3 was identified by mutations that cause a global disruption of touch-receptor differentiation in C. elegans (Chalfie and Sulston 1981). The present results indicate that mec-3 is expressed in several different cell types (the FLP and PVD neurons as well as the six touch receptor neurons): a mec-3-lacZ fusion is expressed in these cells (Fig. 2; Table 1); mec-3(+) is necessary for continued expression of the mec-3-lacZ fusion in all of these cells (Table 1); and mec-3(+) activity is required for function of the touch receptors and PVD, and for the distinctive morphology of the touch receptors (Table 2; Chalfie and Sulston 1981; Way and Chalfie 1988).

All of the mec-3-expressing cells appear to be mechanoreceptors. The ALM, AVM, PVM, and PLM cells mediate the animal's response to gentle touch (Chalfie and Sulston 1981). The PVD neurons mediate a response to a harsher mechanical stimulus (Table 2). The FLP cells have a morphology suggestive of a mechanoreceptor (Ward et al. 1975), but their function has not been tested directly.

mec-3 is required for the differentiation of the touch receptor neurons (Chalfie and Sulston 1981; Way and Chalfie 1988) Without this gene, the touch cells fail to express a number of characteristic morphological features. Moreover, unlike the wild-type touch cells, the mec-3 mutant cells no longer degenerate through the action of dominant mec-4 mutations.

The FLP and PVD cells do not have characteristic features that can be identified without serial section electron microscopic reconstruction. By Nomarski microscopy these cells appear normal [as do several touch receptor neurons in mec-3 mutants (Chalfie and Sulston 1981; Way and Chalfie 1988)]. Thus, we do not know how mec-3 acts in the differentiation and function of the FLP and PVD neurons. We think it likely, however, that mec-3 serves a similar role in these cells and the touch receptor neurons: the specification of cell fate.

\section{Regulation of mec-3 expression}

The expression of the mec-3-lacZ fusion is detectable around the time that the touch receptor neurons and the FLP and PVD cells arise from their respective lineages. Thus, genes that are required for the proper production of these lineages may be good candidates for genes that regulate, directly or indirectly, mec-3 expression. Two genes, lin-32 and unc-86, are required for the appropriate differentiation of precursors in these lineages (Fig. 3; Chalfie et al. 1981; Chalfie and Au 1989; C. Kenyon and E. Hedgecock, pers. comm.). Mutations in these genes result in loss of all (unc-86) or most (lin-32) of the mec-3-expressing cells (see Fig. 3 legend). Behaviorally, these mutants lack the function of both the touch receptor neurons and the PVD cells. Moreover, the unc-86 mutants do not express the mec-3-lac $Z$ fusion. Thus, unc-86 and probably lin-32 are needed for mec-3 expression.

How these genes affect mec-3 expression is unknown. Because they are needed for the differentiation of precursors of the mec-3-expressing cells (for unc-86 some of the affected cells are the direct precursors; see Fig. 3), these genes may act indirectly. Thus, the unc-86 and lin-32-dependent cells may express components necessary for mec-3 expression, perhaps by regulating mec-3 transcription or by controlling the segregation of cellular determinants. It may be significant, in this latter context, that the mec-3-expressing cells are all anterior daughters of asymmetric cell divisions (Sulston and Horvitz 1977; Sulston et al. 1983|. With the rare possible exception of the FLP sister cells (see Methods), the posterior daughters neither express the fusion nor exhibit any mutant phenotype (Fig. 2; Way and Chalfie 1988).

Alternatively, these genes, especially unc-86, may directly regulate mec-3 expression. unc-86 contains a homeo box and has extended homology to mammalian transcription factors Pit-1, Oct-1, and Oct-2, suggesting that it also regulates transcription (Finney et al. 1988). Using the DNA sequences recognized by the mammalian proteins, Finney et al. (1988) identified possible unc- 86 binding sites within the mec-3 gene. The functional importance of these sites has not been tested, but
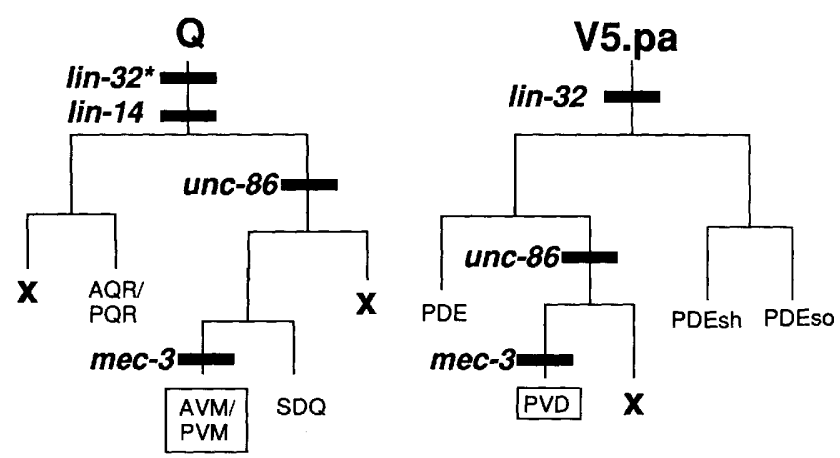

Figure 3. Mutations affecting the lineages giving rise to the AVM and PVM touch receptors and the PVD cells. The two (right and left) Q lineages occur during the first larval stage; the two V5.pa lineages occur during the second. Each lineage gives rise to neurons (designated by their letter names) and cells that undergo programmed cell death $(\mathrm{X})$. In addition, the V5.pa lineage also gives rise to structural cells (PDEsh and PDEso). Genes are positioned on the lineage in association with the cells whose fates appear altered in the respective mutants. This positioning does not necessarily imply the focus of action of these genes. ${ }^{\star}$ lin-32 also affects the precursor of the Q cells. This figure is based on data from the following sources: (lin-14) Ambros and Horvitz (1984); (lin-32) Chalfie and Au (1989) and C. Kenyon and E. Hedgecock (pers. comm.); (unc-86) Chalfie et al. (1981); and (mec-3) Chalfie and Sulston (1981); Way and Chalfie (1988), and data presented in this paper). 
their presence suggests that unc-86 may directly regulate $\mathrm{mec}-3$.

At least one unc-86-dependent lineage does not produce any mec-3 expressing cells: The $\mathrm{T}$ blast cell gives rise to several neurons, none of which express detectable levels of mec-3-lacZ fusion product (Sulston and Horvitz 1977; Chalfie et al. 1981; data presented herein). These results suggest that additional, unidentified regulatory genes restrict mec-3 expression to only a subset of unc-86-dependent lineages (Q and V5 but not $\mathrm{T})$ and to only one of the cells affected by unc- 86 in each of these lineages.

\section{Autoregulation of mec-3}

Autoregulation is a common feature of developmental switch genes. Lambda repressor (Ptashne 1987), Sexlethal (Cline 1984) and Drosophila homeo-box-containing genes such as fushi tarazu (Hiromi and Gehring 1987), Ultrabithorax (Bienz and Tremml 1988), and Deformed (Kuziora and McGinnis 1988) all show autoregulation, albeit by different mechanisms. In each case, autoregulation functions to maintain a determined state during cell proliferation after proteins that induce the initial synthesis of the gene in question are degraded, lost by dilution, or both.

In a mec-3 mutant, expression of the mec-3-lacZ fusion occurs in the correct set of cells at early times. By adulthood, however, no expression of the $1 a c Z$ fusion can be detected, implying that an intact mec-3 gene is necessary for maintenance of mec-3 expression. Unlike the above examples of autoregulation, the mec-3-expressing cells do not divide after mec-3 is expressed. However, the cells enlarge and greatly increase the number of their cell-specific microtubules throughout development (Chalfie and Thomson 1982). Moreover, many genes of the function class have temperature-sensitive periods that span larval development (Chalfie and $\mathrm{Au}$ 1989|. Thus, a continuous supply of mec-3 may be necessary. Such maintenance may be particularly important during periods of arrested development, for example, during starvation.

The effect of mec-3 on its own expression may be direct or indirect. As a homeo-domain-containing protein, the mec-3 product may bind to mec-3 DNA sequences and thus effect further expression. Alternatively, mec-3dependent differentiation of the touch receptor neurons and the FLP and PVD cells may produce cellular environments required for the stability of the mec-3 message or product.

The mec-17 product may also be involved in the maintenance of mec-3 expression, at least in the touch receptor neurons, although any hypothesis about $\mathrm{mec}-17$ must be regarded as tentative because there is only one mutant allele of the gene. The single mec-17 mutation causes initially touch-sensitive animals to become touch-insensitive as they develop (Chalfie and Au 1989). The adult touch receptors in this mutant have a reduced number of the cell-specific microtubules, an indication that their development may have been blocked. In this mutant, expression of the mec-3-lacZ fusion is gradually lost from the touch receptors, but not from the FLP or PVD cells. Thus, mec-17 may be needed for continued mec-3 expression. Alternatively, the mec-17 mutation product may somehow poison the touch receptors so that, as an indirect consequence, protein synthesis is inhibited. Further analysis of the function of mec-17 may require the isolation of null mutants.

\section{Combinatorial determination of cell fate}

$m e c-3$ is expressed in more than one cell type, so it alone cannot regulate cell-specific differentiation. Other factors must act with mec-3 or modify its action so that touch receptors, FLP cells, and PVD cells can be generated. Although the identity of these other factors is unknown, one gene whose product may be required is lin-14. Among other abnormalities, loss of lin-14 gene activity changes the lineages that normally produce the AVM and PVM touch receptors into lineages that produce the PVD cells (Ambros and Horvitz 1984). The lin-14 protein is normally localized to nuclei of the touch receptor precursors, but not to the those of PVD precursors (Ruvkun and Giusto 1989). This product may contribute to the determination of the fate of these postembryonic mec-3-expressing cells.

A number of genes (e.g., mec-4 and mec-7) appear to be selectively expressed in touch receptor neurons, and we have hypothesized that mec-3 is required for their expression (Way and Chalfie 1988). We presume that other mec-3-dependent genes are expressed in the FLP and PVD cells. Because all the cells affected by mec- 3 mutations appear to be mechanoreceptors (although the function of the FLP cells has not been tested), one may expect that some mec-3-dependent genes may be shared by the different cell types. However, none of the genes required for the morphology or function of differentiated touch receptor neurons appears to be required for PVD function (Table 2). Thus, the requirement for mec-3 in these different cell types may not be for the expression of shared components. Perhaps mec-3 activity is modified significantly by other transcription factors so that completely different sets of genes are activated in the various cell types. Further analysis of mec-3, its regulators, and targets may help elucidate how this gene specifies the differentiation of such morphologically distinct neurons.

\section{Methods \\ Growth and maintenance of strains}

All C. elegans strains were propagated as described in Way and Chalfie (1988) and Brenner (1974).

\section{Mutant strains}

All of the mec mutant strains, and egl-5(u202) and lin-32(u282) are described in Chalfie and $\mathrm{Au}(1989)$ and references therein. ced-1(e1735) (Hedgecock et al. 1983) was obtained from the lab of H.R. Horvitz. unc-24(e138) mec-3(u467) dpy-20(e1282) is described in Way and Chalfie (1988). 


\section{DNA constructions}

Plasmids pTU41-pTU51 (Fig. 1) were constructed by BAL-31 exonuclease digestion followed by religation in the presence of NotI linkers of pTU28 from the following unique restriction sites: BgIII (pTU4l, pTU42); ClaI (pTU46); SalI (pTU48, pTU49, pTU51). All these plasmids received NotI linkers except pTU48. Extents of deletion were determined by restriction digestion with NotI and other appropriate enzymes, except for pTU48, which was analyzed with Sau3A. The sizes of the resulting restriction fragments were estimated within an accuracy of $50 \mathrm{bp}$. pTU37 was constructed by ligation of the mec-3containing ScaI-Sacl fragment from pTU23 [base pairs 910-5660 on the sequence of Way and Chalfie 1988)] into EcoRV, SacI cut pIBI30 (International Biotechnologies Incorporated).

\section{Construction of $\mathrm{uEx} 4$}

To construct a mec-3-lacZ fusion, a lacZ-containing DNA fragment was inserted into pTU48, which carries the entire mec-3 gene. pTU48 has an intact mec- 3 gene, as defined by rescue of touch sensitivity following transformation, and contains base pairs $-2,000$ to +5660 of the mec-3 sequence (Way and Chalfie 1988). Furthermore, it is possible to delete up to base pair +1495 , from the $5^{\prime}$ end of mec-3, back to base pair 5030 , from the 3 ' end, or from base pair 2335 to 2580 internally, and still retain $m e c-3$ gene function (as assayed by rescue of touch sensitivity following transformation). Thus, it seemed reasonable that pTU48 would contain sequences sufficient for accurate mec-3 gene expression. pTU28 was constructed by insertion of a XhoI-Sall lacZ fragment from PS118 (Silver et al. 1988 ) into the unique Xhol site in pTU48, generating an inframe translational fusion between the homeo box of mec-3 and $1 a c Z$.

Equal amounts of pTU28 and pPD10.41, a plasmid that expresses an unc-22 antisense RNA and that causes transformed C. elegans to twitch (A. Fire, pers. comm.), were coinjected at a concentration of $100 \mathrm{ng} / \mu \mathrm{l}$ into wild-type C. elegans according to Fire (1986). One transformed animal was identified that contained a mixed array of pTU28 and pPD10.41, with $\sim 40$ copies per cell of each plasmid, as determined by Southern blotting (data not shown). This array, termed $u E x 4$, behaves genetically as a free duplication: It has an inheritance rate of about $50 \%$ per generation, and animals carrying it often appear to be genetic mosaics. This element has been propagated for over 50 generations and crossed into several mutant backgrounds, always followed by direct screening for the twitching phenotype and subsequent checking for $\beta$-galactosidase activity. No line has ever been identified that completely fails to express $\beta$-galactosidase activity. $u E_{X} 4$ has been crossed from a wild-type background into unc-24 mec-17 and back into wild type without a change in the wild-type staining pattern.

\section{Identification of cells with $\beta$-galactosidase activity}

$C$. elegans strains carrying $u E x 4$ were stained with the $\beta$-galactosidase substrate X-gal and the fluorescent nuclear stain 4,6diamidino-2-phenylindole dihydrochloride (DAPI), according to a procedure developed by A. Fire (pers. comm.). Stained animals were observed with a Zeiss Universal microscope using brightfield and fluorescence illumination. Cells were scored as staining if any observable blue precipitate was present.

Stained cells were identified by their overall positions within the animal, their positions relative to other neuronal nuclei, their time of appearance, and their absence in certain mutants (Table 1). Cells were identified according to White et al. (1986). Each FLP neuron was found in a characteristic position in a row of nuclei lateral to the rear bulb of the pharynx. Each PVD cell was the most anterior neuron in the post-deirid cluster (Sulston and Horvitz 1977; White et al. 1986; H.R. Horvitz, pers. comm.). Each PLM was located in a large cluster of neurons posterior to the anus. The identification of this staining cell was also based on its absence in the mec4(d) mutant. Each ALM was found dorso-lateral and anterior to the vulva, and did not have a fixed geometry relative to its neighbors because it underwent a long posterior migration. The identification of this cell was based on its absence in $m e c-4(d)$ and the fact that it was the only neuron evident in this general region of the animal. AVM was found to be ventro-lateral, about halfway between the vulva and the rear bulb of the pharynx. This cell, which does not have a fixed position relative to its neighbors due to migration of its precursors, is the only neuron in this vicinity, and is absent in $m e c-4(d)$. PVM was intercalated into the postdeirid cluster in a variable position, because it arose at a different time from other post-deirid neurons. This cell was absent in mec-4(d). AVM and PVM were also identified by the fact that they were not bilaterally symmetric (AVM was only on the right side, PVM on the left), and because staining of these neurons was first seen in the late $\mathrm{L} 1$ stage.

Individuals containing $u E x 4$ were identified as twitchers, either by visual inspection, the nicotine assay of Moerman and Baillie (1979), or by the Mec phenotype of twitchers /Chalfie and Sulston 1981), then picked into staining solution and stained overnight at $37^{\circ} \mathrm{C}$. Because the $u E x 4$ element is a free duplication, its copy number could vary and lead to variations in $\beta$-galactosidase expression. To select for animals that would have the highest copy of $u E_{X} 4$, we generally stained animals with the most severe Twitcher phenotype, that is, animals that could be seen to twitch without nicotine. Such animals can be recognized during adulthood and the L4 larval stage, but not at earlier stages. Twitching appears to habituate the touch receptor cells (Chalfie and Sulston 1981). We do not feel, however, that the unc-22 antisense construct significantly affects the expression of the mec-3-lacZ fusion because the touch receptors in otherwise wild-type animals are functional (a touch response can sometimes be elicited) and because the cells degenerate in the mec-4(d) background.

In some experiments, no effort was made to select extreme Twitchers, and the staining was less complete. This variation may account for the apparent overall reduction in staining in the wild-type L2/L3 animals in Table 1 . In addition, animals stained for less that $15 \mathrm{hr}$ often had a reduced frequency of staining cells (data not shown). The low frequency of staining of the AVM and PVM cells probably resulted from insufficient levels of mec-3-lacZ expression (staining of these cells was often weakl, and not from somatic loss of $u E x 4$, because such loss should occur just as often for PVD as for AVM and PVM. When animals were raised at $25^{\circ} \mathrm{C}$, either the entire set of cells were stained, or the animals were clearly mosaic (Table 1). Growth at this temperature may stabilize the $\beta$-galactosidase activity of the mec-3-lac $Z$ fusion or may reduce the frequency of somatic loss of the $u E x 4$ element.

Many animals appear to be genetic mosaics in that an incomplete set of cells stained. Among $25 \mathrm{uEx} 4$ animals raised at $25^{\circ} \mathrm{C}$ (Table 1), 5 appeared to have lost $u E x 4$ during somatic cell divisions. One lost the element between ABpr and ABprapa (no FLPR, PVDR, AVM, or PLMR staining), one lost it between $A B p l$ and ABplapa (no FLPL, PVDL, PVM, or PLML staining), one between $\mathrm{ABa}$ and $\mathrm{ABarpp}$ (no ALM staining), and two appeared to have lost $u E x 4$ in the QL/V5L precursor (no PVDL or 
PVM staining). Among animals raised at $20^{\circ} \mathrm{C}$, the pattern of unstained cells could not be rationalized by single loss events. We do not know if these animals sustained multiple losses of the free duplication, or whether some cells expressed $\beta$-galactosidase activity below the threshold of detection.

\section{Crossing the uEx 4 element into mutant backgrounds}

The uEx4 element was crossed into mec-3(u298), unc-86(e1416), mec-4(e1611), and egl-5(u202) mutant backgrounds by a two-step procedure. These constructions were complicated by the fact that the twitching of $u E x 4$-containing animals reduces male mating (Hodgkin 1983) and results in a Mec phenotype (Chalfie and Sulston 1981). Wild-type males were mated with each mutant and heterozygous male progeny were mated into $u E x 4$ animals to generate a $+/ \mathrm{m} ; u E x 4$ crossprogeny. Because these animals could not be distinguished from other types of cross- or self-progeny, 50 to 75 twitching (uEx4-containing) hermaphrodites were picked to separate plates and screened for segregation of one-quarter of $\mathrm{m} / \mathrm{m}$ animals among the nontwitching progeny. $m / m$; $u E x 4$ animals were identified as twitching animals whose nontwitching progeny were all $\mathrm{m} / \mathrm{m}$. (In addition to the strains discussed in Results, egl-5; uEx4 animals were also examined and showed the wild-type staining pattern.)

Because the mec-17(u265) phenotype is difficult to score, a mec-17; uEx4 strain was constructed with the aid of the linked marker unc-24(e138). mec-17 maps about $0.1 \mathrm{cM}$ to the right of unc-24: 1 of 10 Unc recombinants and all three Dpy recombinants from $+m e c-17++/$ unc-24 $+m e c-3$ dpy-20(e1282) contained the mec-17 mutation on the recombinant chromosome, as determined by progeny testing and test mating with mec-17; him-5(e1490) males.

An unc-24 mec-17; $u E \times 4$ strain was constructed and tested in the same way as the mec; uEx4 strains described above. mec-17; him-5 males were mated into this strain, and nonUnc-24, twitching progeny were identified (+ mec-17) unc-24 mec-17; $u E x 4$ ), from which mec-17; $u E x 4$ animals were obtained by segregation.

A ced-1; mec-3 strain was constructed by mating spontaneous ced-1(e1735) males with mec-3(u298) hermaphrodites. From non-Mec +/ mec-3; +/ ced-1 hermaphrodite crossprogeny, Mec Ll self-progeny were identified and screened for the presence of persistent cell deaths (the Ced-1 phenotype) using Nomarski optics. One mec-3; ced-1 animal was thus identified and used to test for the presence of cell deaths in the post-deirid region (see results).

\section{Behavioral assay for sensitivity to strong mechanical stimuli}

To test for sensitivity to harsh touch, non-moving gravid adults were prodded with a platinum wire at or just posterior to the vulva. Animals with a functional PVD neuron moved, usually backing up, whereas animals lacking this neuron did not respond. Only Mec mutants (mutants that lack touch receptor function and do not respond to gentle touch with an eyebrow hair; Chalfie and Sulston 1981; Chalfie and Au 1989/ have been tested in this way: Functional touch receptors would otherwise mediate a vigorous response to this stimulus. Mec animals lacking PVD still respond when prodded at the tail or in the region of the pharynx. Animals tested were grown from hatching in the presence of food at $20^{\circ} \mathrm{C}$. Animals recovering from the dauer state or a starved state often fail to respond regardless of the presence of the PVD neurons.

In several experiments (Table 2), approximately equal numbers of sensitive and insensitive animals were scored blind.

\section{Laser ablation}

Cells were ablated essentially as described in Sulston and White (1980), except that a Laser Science VS337 laser was used and 50-100 pulses were used to kill each cell. The V4 and V5 cells were killed in newly hatched animals $(<5 \mathrm{hr}$ old $)$ by killing the cell on the upper side of the animal, then focusing through the animals and killing the cell on the other side. The PVD and other post-deirid cells were killed in L3 animals. After ablation of PVD on one side of the animal, the animals were allowed to recover, were remounted, and the cell on the other side was ablated.

\section{Acknowledgments}

We wish to thank A. Fire for plasmids, procedures, and advice about expression of lacZ in C. elegans; Geraldine Seydoux and Iva Greenwald for help with the laser ablations, and Mark Osborne and Iva Greenwald for reading the manuscript. This research was supported by National Institutes of Health (NIH) grant GM30997 to M.C., NIH Post-doctoral Fellowship, Merck Research Fellowship, and NIH First Award HD25557 to J.C.W.

\section{References}

Akam, M. 1987. The molecular basis for metameric pattern in the Drosophila embryo. Development 101: 1-22.

Ambros, V. and H.R. Horvitz. 1984. Heterochronic mutants of the nematode Caenorhabditis elegans. Science 226: 409416.

Bienz, M. and G. Tremml. 1988. Domain of Ultrabithorax expression in Drosophila visceral mesoderm from autoregulation and exclusion. Nature 333: 576-578.

Brenner, S. 1974. The genetics of Caenorhabditis elegans. Genetics 77: 71-93.

Chalfie, M. and J. Sulston. 1981. Developmental genetics of mechanosensory neurons of Caenorhabditis elegans. Develop. Biol. 82: 358-370.

Chalfie, M., H.R. Horvitz, and J.E. Sulston. 1981. Mutations that lead to reiterations in the cell lineages of $C$. elegans. Cell 24: 59-69.

Chalfie, M. and J.N. Thomson. 1982. Structural and functional diversity in the neuronal microtubules of Caenorhabditis elegans. I. Cell Biol. 93: 15-23.

Chalfie, M., J.E. Sulston, I.G. White, E. Southgate, J.N. Thomson, and S. Brenner. 1985. The neural circuit for touch sensitivity in Caenorhabditis elegans. I. Neurosci. 5: 956964.

Chalfie, M. and M. Au. 1989. Genetic control of differentiation of the Caenorhabditis elegans touch receptor neurons. Science 243: 1027 - 1033 .

Cline, T.W. 1984. Autoregulatory functioning of a Drosophila gene product that establishes and maintains the sexually determined state. Genetics 107: 231-277.

Ellis, H.M. and H.R. Horvitz. 1986, Genetic control of programmed cell death in the nematode C. elegans. Cell 44: 817-829.

Finney, M. 1987. PhD. The genetics and molecular biology of unc-86, a C. elegans cell lineage gene. Thesis, Massachusetts Institute of Technology, Cambridge, Massachusetts.

Finney, M., H.R. Horvitz, and G. Ruvkun. 1988. The C. elegans cell lineage and differentiation gene unc-86 encodes a protein with a homeodomain and extended similarity to transcription factors. Cell 55: 757-769.

Fire, A. 1986. Integrative transformation of Caenorhabditis elegans. EMBO J. 5: 2673-2680. 
Hedgecock, E., J.E. Sulston, and J.N. Thomson. 1983. Mutations affecting programmed cell deaths in the nematode Caenorhabditis elegans. Science 220: 1277-1280.

Herman, R.K. 1984. Analysis of genetic mosaics of the nematode Caenorhabditis elegans. Genetics 108: 165-180.

Herman, R.K. 1987. Mosaic analysis of two genes that affect nervous system structure in Caenorhabditis elegans. Genetics 116: 377-388.

Herskowitz, I. 1988. Life cycle of the budding yeast Saccharomyces cerevisiae. Microbiol. Rev. 52: 536-553.

Hiromi, Y. and W.J. Gehring. 1987. Regulation and function of the Drosophila segmentation gene fushi tarazu. Cell 50: $963-974$.

Hodgkin, J. 1983. Male phenotypes and mating efficiency in Caenorhabditis elegans. Genetics 96: 649-664.

Ingham, P.W. 1988. The molecular genetics of embryo pattern formation in Drosophila. Nature 335: 25-33.

Kuziora, M.A. and W. McGinnis. 1988. Autoregulation of a Drosophila homeotic selector gene. Cell 55: 477-485.

Moerman, D.G. and D.L. Baillie. 1979. Genetic organization in Caenorhabditis elegans: Fine structure mapping of the unc-22 gene. Genetics 91: 95-104.

Ptashne, M. 1987. A genetic switch: Gene control and phage. Blackwell Scientific Publishing, Inc. Palo Alto, California.

Ruvkun, G. and J. Giusto. 1989. The Caenorhabditis elegans heterochronic gene un-14 encodes a nuclear protein that forms a temporal developmental switch. Nature 338: 313319.

Silver, P., A. Chiang, and I. Sadler. 1988. Mutations that alter both localization and production of a yeast nuclear protein. Genes Dev. 2: 707-717.

Stinchcomb, D.T., I.E. Shaw, S.H. Carr, and D. Hirsh. 1985. Extrachromosomal DNA transformation of $C$. elegans. Mol. Cell. Biol. 5: 3484-3496.

Sulston, J. and H.R. Horvitz. 1977. Post-embryonic cell lineages of the nematode Caenorhabditis elegans. Develop. Biol. 56: $110-156$.

Sulston, J.E. and J.G. White. 1980. Regulation and cell autonomy during post-embryonic development of Caenorhabditis elegans. Develop. Biol. 78: 577-597.

Sulston, J.E., E. Schierenberg, J.G. White, and J.N. Thomson. 1983. The embryonic cell lineage of the nematode Caenorhabditis elegans. Develop. Biol. 100: 64-119.

Ward, S., N. Thomson, J.G. White, and S. Brenner. 1975. Electron microscopical reconstruction of the anterior sensory anatomy of the nematode Caenorhabditis elegans. I. Comp. Neurol. 160: 313-338.

Way, J.C. and M. Chalfie. 1988. mec-3, a homeo-box-containing gene that specifies differentiation of the touch receptor neurons in C. elegans. Cell 54:5-16.

White, J.G., E. Southgate, J.N. Thomson, and S. Brenner. 1986. The structure of the nervous system of the nematode Caenorhabditis elegans. Phil. Trans. Roy. Soc. Lond. 314: 1-340. 


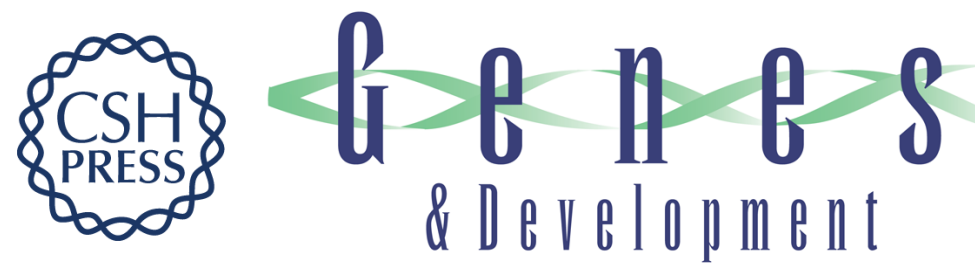

\section{The mec-3 gene of Caenorhabditis elegans requires its own product for maintained expression and is expressed in three neuronal cell types.}

J C Way and M Chalfie

Genes Dev. 1989, 3:

Access the most recent version at doi:10.1101/gad.3.12a.1823

References This article cites 31 articles, 14 of which can be accessed free at:

http://genesdev.cshlp.org/content/3/12a/1823.full.html\#ref-list-1

License

Email Alerting Service

Receive free email alerts when new articles cite this article - sign up in the box at the top right corner of the article or click here.

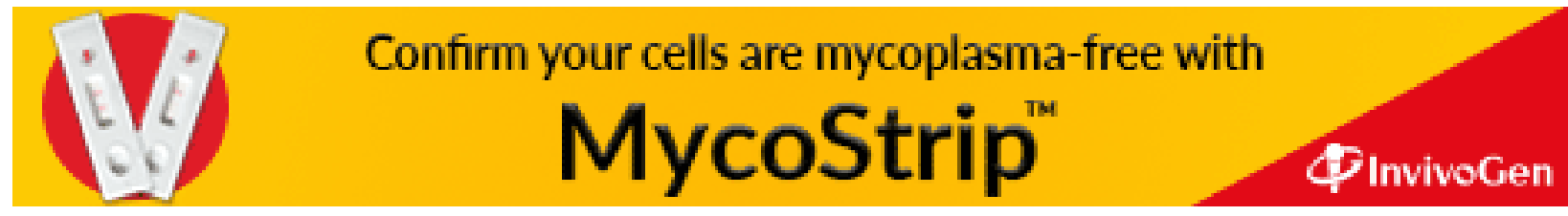

